\title{
Mathematical Analysis of Improving the System Capacity and Signal to Interference Ratio in Cellular Mobile Communication
}

\author{
Md. Ariful Islam ${ }^{1 *}$, Amena Begum² and Md. Rakib Hasan ${ }^{2}$ \\ ${ }^{1}$ Dept. of Robotics \& Mechatronics Engineering, University of Dhaka, Dhaka, Bangladesh \\ ${ }^{2}$ Dept. of Information \& Communication Technology, Comilla University, Cumilla, Bangladesh
}

Received: January 01, 2021, Revised: January 28, 2021, Accepted: January 30, 2021, Available Online: February 06, 2021

\begin{abstract}
The most important index for Quality of Service (e.g. reliability, performance) is call drop which has not been accurately discussed before. Sometimes the network disconnects while talking on the phone, this disconnection is called a dropped call. The level of call drop of mobile operators in the every country has increased significantly lately. As a result, thousands of mobile phone users are suffering. To reduce call drop, at first the factors causing call drop have been identified in this paper. Based on these factors, a dropped call model has developed to find out the parameters associated with call drop. Then some existing techniques have analyzed mathematically to improve the different parameters of these factors to reduce call drop. Three main factors have been identified from the developed dropped call model causing call drops such as the lack of available channels, the poor signal quality and the handover failure. In this paper, mathematical analysis of cell splitting, cell sectoring and microcell zone concept have been provided to support extra connecting demand, ongoing service and to improve the signal to interference ratio. Also queuing handoff will be analyzed mathematically with justification to avoid disturbing service call drop. Simulation of a mathematical model of these call drop reduction techniques has performed using MATLAB software.
\end{abstract}

Keywords: Cell Splitting; Cell Sectoring, Microcell Zone Concept, Quality of Service, Capacity, Signal to Interference Ratio.

This work is licensed under a Creative Commons Attribution-Non Commercial 4.0 International

\section{Introduction}

Mobile companies cannot afford a large amount of network demands with increasing population density day by day [1]. For these reasons force termination of calls has to be implemented to support the traffic-congested area. So, now-a-days call drop reduction becomes our the main goal to ensure the best service in the wireless communication system. For call drop reduction, at first the factors causing call drop will have to be investigated. With the help of this investigation, the solution of call drop will be provided with mathematical proof. This research may help steer the mobile operators to improve the quality of the service with existing techniques that they will provide.

Puru Gaur [1] published a paper on a review of menace of call drops in India and possible ways to minimize it. In that paper, they demonstrated the overall condition of call drops and possible ways such as cell splitting, cell sectoring, dynamic channel allocation and hybrid channel allocation were provided to minimize the call drops. But they did not give any mathematical proof analysis of their proposed methods. Ohaneme C.O, Onoh G.N, Ifeagwu E.N and Eneh [2] presented cell splitting as a technique of improving channel capacity and reducing blocking probability. But any solution regarding the signal to interference ratio problem was not provided. Jatin and Karishan Kumar [3] analyzed call dropping and handover problem in the cellular system. But any solution based on a mathematical model was not mentioned. This paper deals with various techniques such as cell splitting, cell sectoring, microcell zone concept and queuing handoffs mechanism with a view to minimizing call drop probability within high density traffic area. The service coverage area has been maximized and interference has minimized in this work. The existing techniques will be verified mathematically.

\section{Methodology}

\subsection{Identify factors causing call drop}

To develop a model to reduce call drop, the factors causing call drop have to be identified. The factors which are responsible casing call drop are given as follows.

\subsubsection{Increasing demand of wireless cellular connectivity}

The blocking probability increases with increasing the offered traffic intensity. This relationship can be found from Erlang B formula [4] given by equation (1)

$$
\begin{aligned}
& B(M, A)=\frac{A^{M} / A !}{\sum_{i=0}^{M}\left(\frac{A^{i}}{i !}\right)} \Rightarrow M \\
& =\frac{\log \left[B(M, A) \sum_{i=0}^{M}\left(\frac{A^{i}}{i !}\right)\right]}{\log A} \times A !
\end{aligned}
$$

Where, $B(M, A)$ is the lost call probability, $A$ is the traffic intensity which is offered in Erlangs and $M$ is the available number of channels.

\subsubsection{Handover Failure}

According to Hong and Rappaport model [5] the handoff rate is given by equation (2)

$$
\lambda_{H A R}=\frac{P_{N C O H}\left(1-B_{\text {originating }}\right)}{1-P_{S H C}\left(1-P_{\text {failure }}^{\prime}\right)} \lambda_{\text {originatig }}
$$


Where, $\lambda_{H A R}$ is the handoff arrival rate, $P_{N C O H}$ is the probability of a new call required at least one handoff, $P_{S H C}$ is the probability of successfully handed call required another call, $B_{\text {originating }}$ is the originating call blocking probability, $P_{\text {failure }}^{\prime}$ is the handoff failure probability, $\lambda_{\text {originating }}$ is the originating arrival call rate. If proper handover cannot be ensured, call drop occurs. Basically handover failure can be occurred due to mismanagement of cell allocation scheme of incoming requested call to be switched into another base station cell.

\subsubsection{Lack of signal strength}

When a user enters an area which is out of coverage or having inadequate signal strength or the place where the signals are interfered, interrupted or jammed may cause call drop [1].

\subsubsection{Co-channel Interference}

The signal to interference ratio may be reduced due to cochannel interference which can be realized from the equation (3) [1].

$$
\begin{aligned}
\frac{S}{I}=\frac{(3 N)^{\gamma / 2}}{6} \Rightarrow \frac{S}{I} & =\frac{1}{\sum_{l=1}^{6}\left(\frac{D_{l}}{R}\right)^{-\gamma}} \Rightarrow \frac{S}{I}=\frac{1}{6(q)^{-\gamma}} \\
& =\frac{q^{\gamma}}{6}
\end{aligned}
$$

Where, $D_{l}$ is the distance between $l^{\text {th }}$ interfering cell and mobile station, $N$ is the cluster size, $R$ is the cell radius, $\gamma$ is the path loss exponent and $q$ is the frequency reuse ratio.

\subsection{Dropped call model}

Now dropped call model can be developed considering the factors that have previously discussed. Let, $\kappa_{t}$ is the total entering traffic. A fraction of this entering traffic will be dropped which is known as dropped call probability denoted by $P_{\text {drop }}$. Then the relation between the dropped call rate and dropped call probability [6] can be shown by equation (4)

$$
D_{r}=\kappa_{t} \times P_{d r o p}
$$

The channel utilization factor $\varrho$ is the ratio of traffic intensity to the number of channels and it can be found [6] by equation (5)

$$
\varrho=\frac{\kappa_{t}}{M}
$$

The dropped call probability $P_{\text {drop }}$ can be modeled [4] as given in equation (6)

$$
P_{\text {drop }}=1-\frac{1}{e^{\varrho}-1} \sum_{l=1}^{\infty} \frac{\varrho^{l}}{l !} \int_{0}^{\infty} f_{T}(t) e^{-\frac{D_{r} t}{l}} d t
$$

The model has revealed that the dropped call probability depends on the dropped call rate $D_{r}$, the utilization factor $\varrho$ and the probability density function $f_{T}(t)$ of call duration which is normally terminated.

Dropped call rate and Dropped call probability can be calculated with the help of equations (4) and (6). According to equation (4) and (6), the relationship between dropped call rate, dropped call probability and network traffic can be established shown in Fig. 1. As the network traffic increases, the dropped call rate and probability increase gradually.
With different number of active users, the dropped call probability can be calculated from equation (6). For reducing Dropped Cal Probability, the capacity should be increased to support large number of users. According to equation (6), the dropped call probability increases as the number of active user increases gradually shown in Fig. 2.

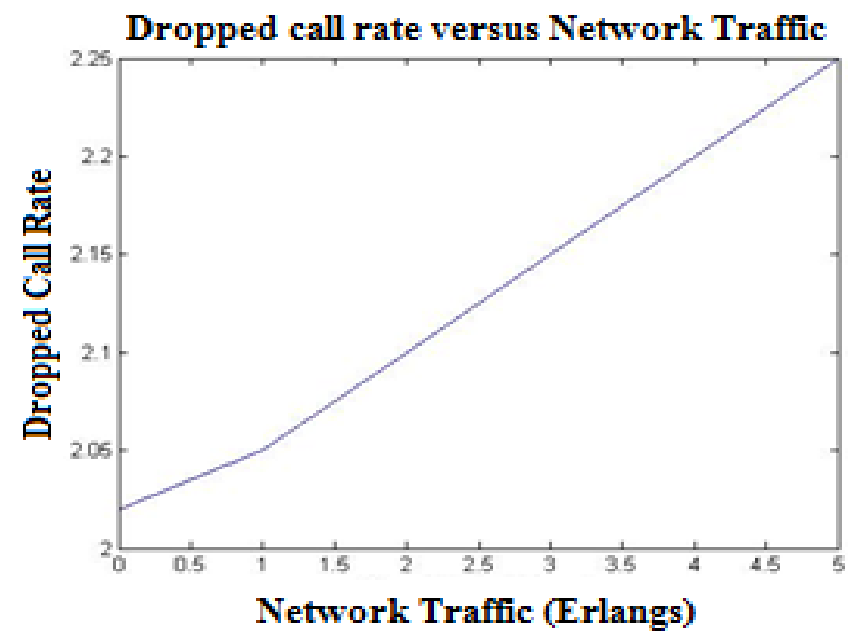

(a)

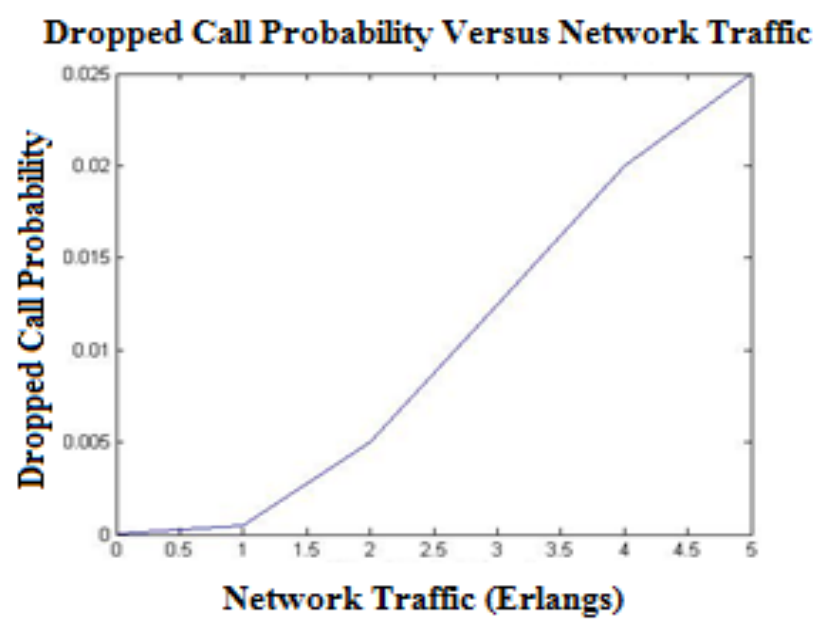

(b)

Fig. 1 Graph of (a) Dropped call rate versus Network traffic, (b) Dropped call probability versus Network traffic.

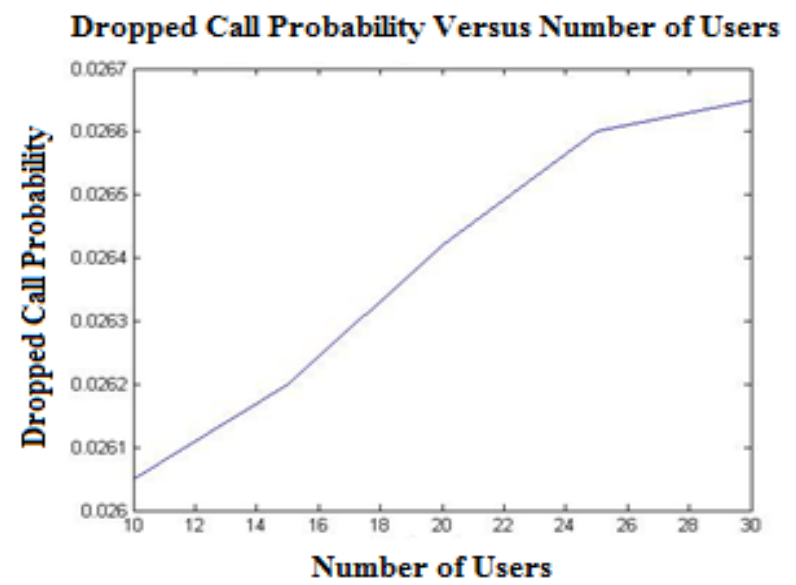

Fig. 2 Dropped call probability versus number of active users. 
Channel Utilization Factors can be found from equation (5) and with channel utilization factor $(\varrho)$, the dropped call probability can be calculated from equation (6). From equation (5), the channel utilization factor depends on the total traffic. As the traffic intensity increases, the channel utilization factor also increases with the given number of channels and as a result the dropped call probability decreases which can be evaluated from the equation (6) shown in Fig. 3.

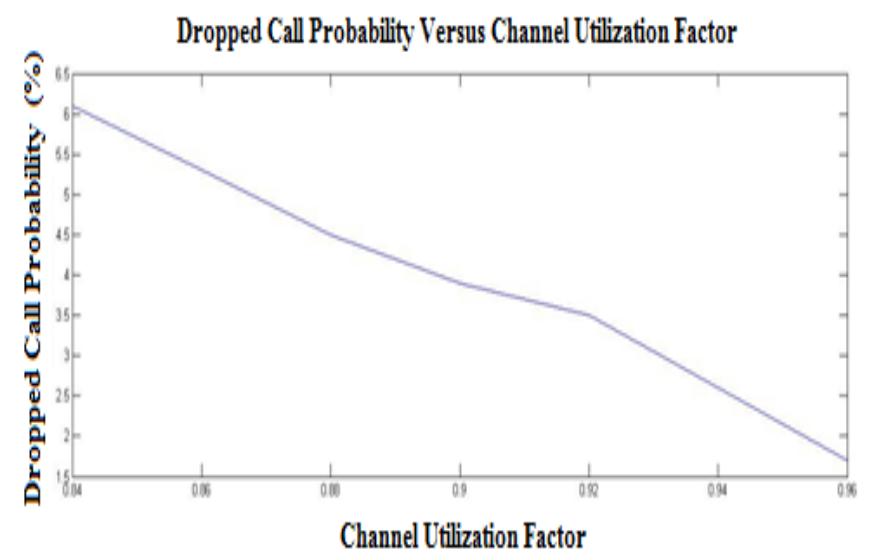

Fig. 3 Dropped call probability versus channel utilization factor.

\subsection{Analysis of Techniques to reduce call drop}

Based on the dropped call probability model, different techniques such as cell splitting, cell sectoring and microcell zone concept can be applied to reduce the call drop. Here, the mathematical justification of these techniques have analyzed so that a network designer can design a cellular network based on this study.

\subsubsection{Cell Splitting}

When a large congested cell is subdivided into smaller cells with its own base station, the antenna height and transmitting power will be reduced. This process is known as cell splitting shown in Fig. 4. In cell splitting, the congested cells are subdivided into micro, pico and femto cells with own base station [4].

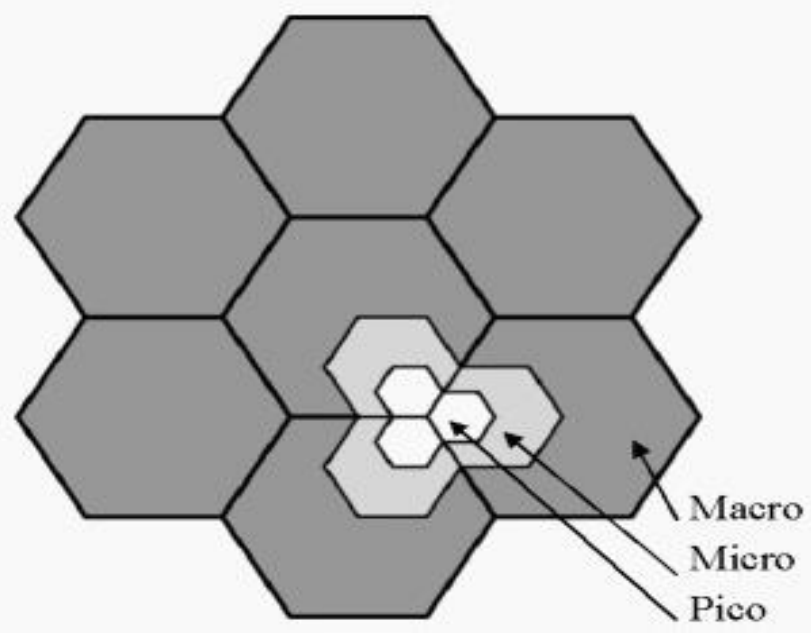

Fig. 4 Cell splitting [4].

A base station covers the radio area which is known as cell. Cell can be in different shapes shown in Fig. 5.
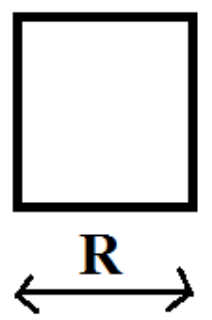

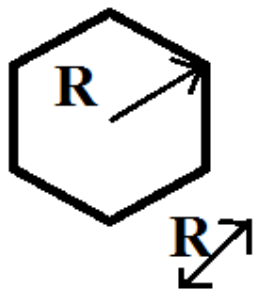

Fig. 5 Different cell model [4].

In most modeling and simulation, hexagonal cells [4] are used. The area of hexagon can be found by

$$
\text { Area }_{\text {hexagon }}=\frac{3 \sqrt{3} R^{2}}{2}
$$

Two shift parameters $i$ and $j$ (values can be $0,1,2 \ldots, n$.) are used to find out the location of co-channel cell located in the neighborhood region separated by $60^{\circ}$ shown in Fig. 6 and Fig. 7.

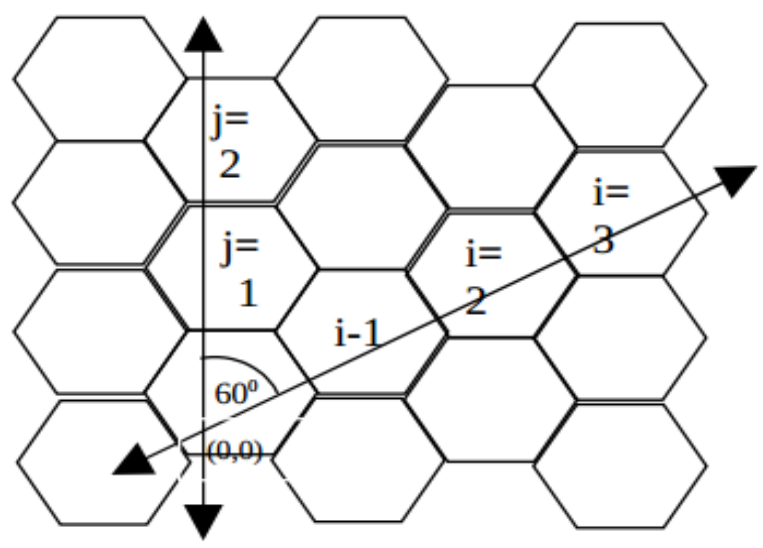

Fig. 6 Shift Parameters i and j in hexagonal network.

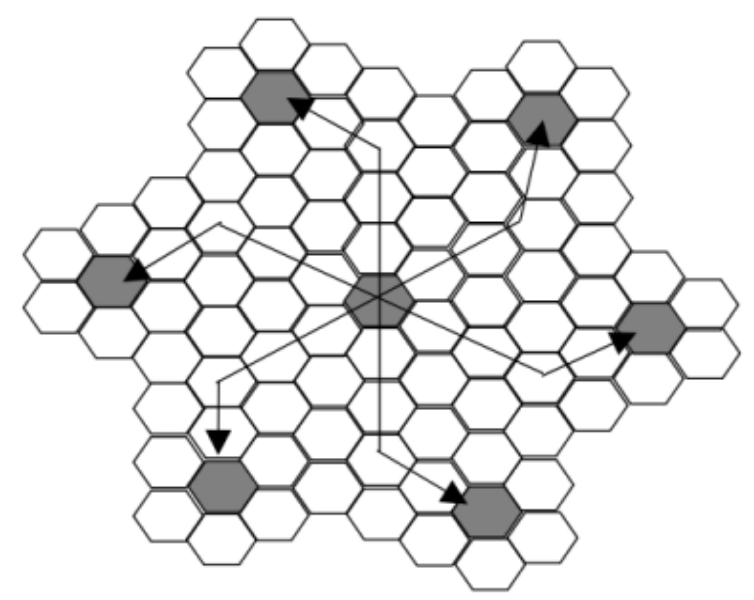

Fig. 7 Locating co-channel cells when $i=3 \& \mathrm{j}=2$.

To develop the relationship between cluster size and shifting parameters $i$ and $j$, let $R$ be the distance between the center of a regular hexagon to any of its vertex and $d$ be the distance between the centre of two neighboring hexagons, and following steps are followed while calculating the size of a cluster $N$. 


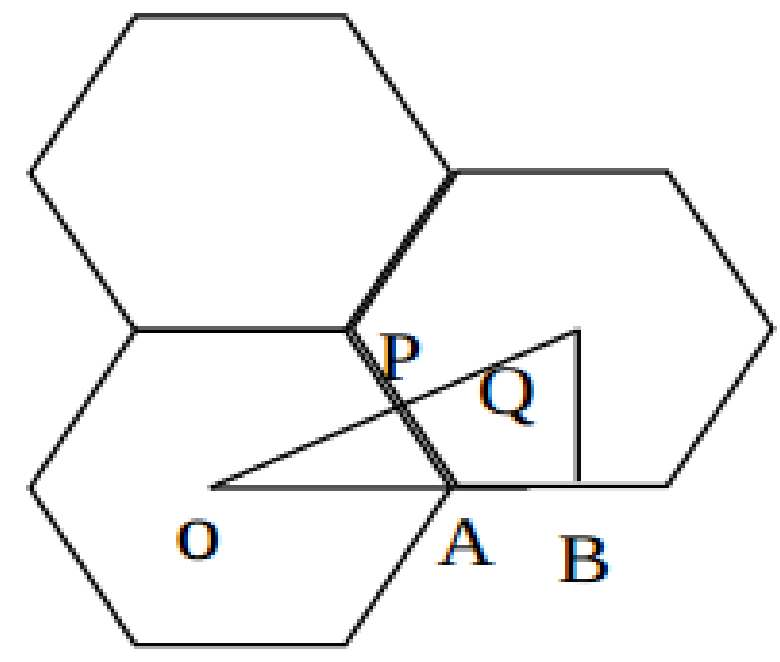

Fig. 8 Distance between two adjacent cells.

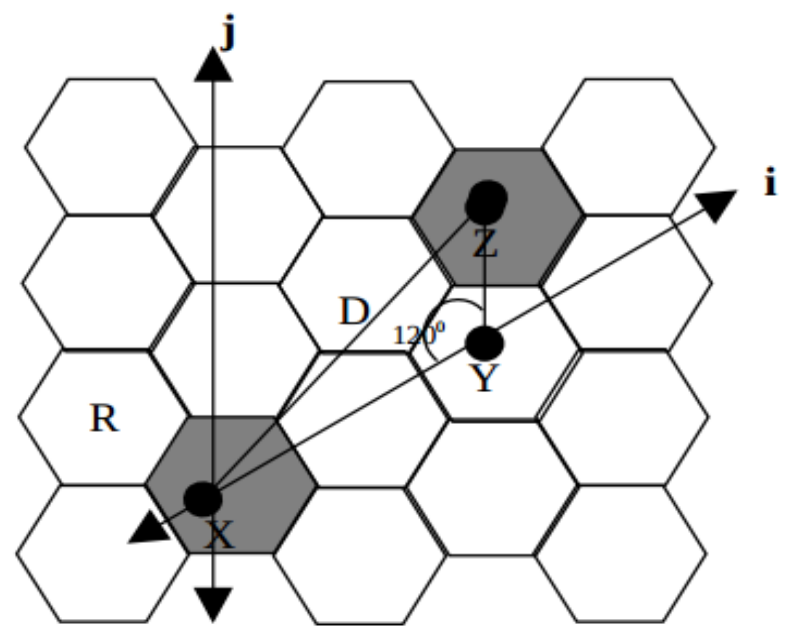

Fig. 9 Relationship between $\mathrm{N}$ and shift parameters (i \& j).

From the geometry of the Fig. 8, $O A=R$ and $A B=R / 2$. Then, $O B=O A+A B=R+R / 2=3 R / 2$. In rightangled $\triangle O A P, O P=O A \sin 60^{\circ}=\frac{\sqrt{3}}{2} R$. Let the distance between the centers of two neighboring hexagonal cells, $O Q$, be denoted by $d$, then, $O Q=O P+P Q($ where $O P=P Q)$.

Therefore, $d=\left[\frac{\sqrt{3}}{2} R+\frac{\sqrt{3}}{2} R\right]=\sqrt{3} R$.

The area of a hexagonal cell with radius $\mathrm{R}$ is given as $A_{\text {small hexagon }}=\left(\frac{3 \sqrt{3}}{2}\right) R^{2}$. Using cosine formula $\triangle X Y Z$ in Fig. 9, we have, $X Z^{2}=X Y^{2}+Y Z^{2}-2(X Y)(Y Z) \cos 120^{\circ}$

$$
\begin{aligned}
& \Rightarrow D^{2}=(i \times d)^{2}+(j \times d)^{2}-2(i \times d)(j \times \\
& \text { d) }\left(-\frac{1}{2}\right)=3 R^{2}\left(i^{2}+j^{2}+i \times j\right)
\end{aligned}
$$

Where, $D$ is the distance between a particular cell and nearest co-channel cells. To find the area of a large hexagon, $A_{\text {large hexagon }}$, joining the centers of the six nearest neighboring co-channel cells, a large hexagon is formed with radius equal to $\mathrm{D}$, which is also the co-channel cell separation shown in Fig. 10.

The area of the large hexagon having a radius of $\mathrm{D}$ can be given as

$$
\begin{aligned}
A_{\text {large hexagon }=} & \left(\frac{3 \sqrt{3}}{2}\right) \times R^{2}=\left(\frac{3 \sqrt{3}}{2}\right) \times D^{2} \\
& =\left(\frac{3 \sqrt{3}}{2}\right) \times 3 R^{2}\left(i^{2}+j^{2}+i \times j\right)
\end{aligned}
$$

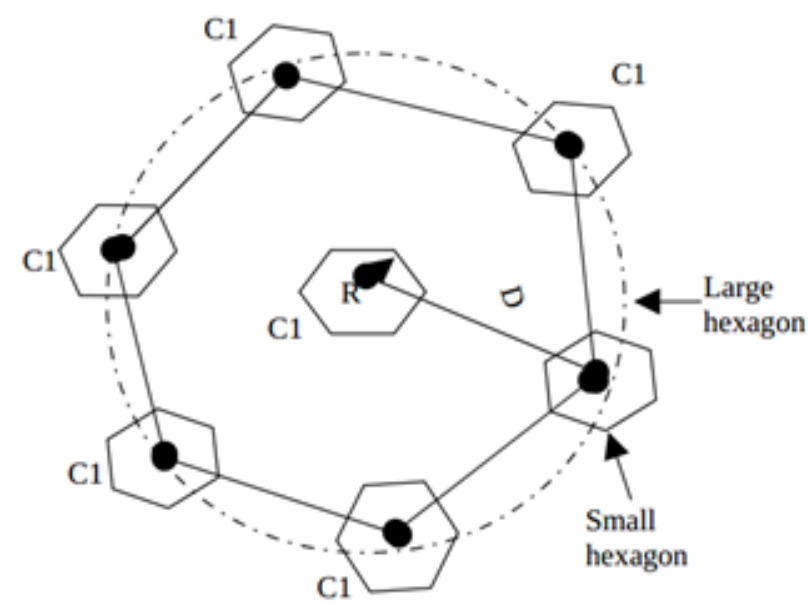

Fig. 10 Larger hexagon in the first tie [4].

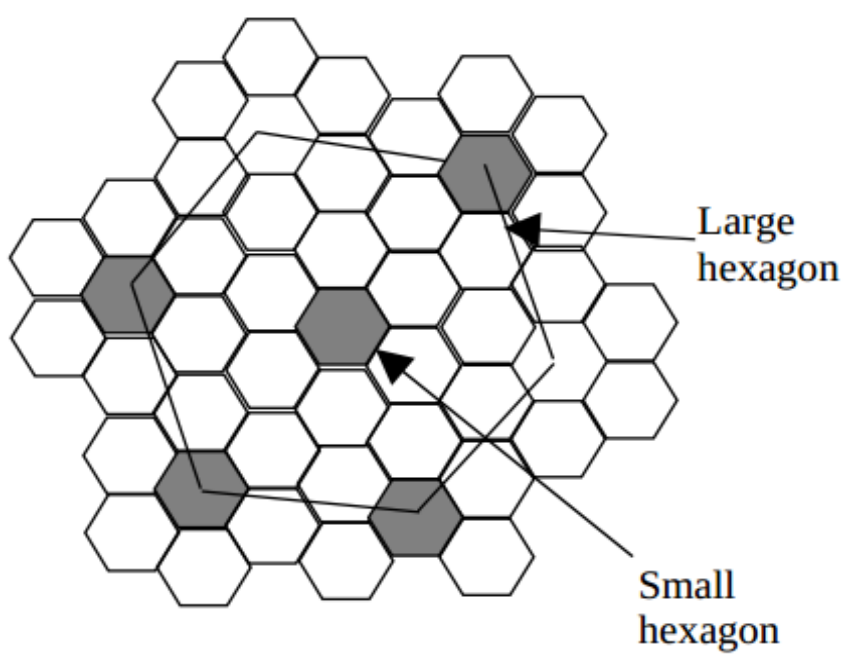

Fig. 11 Number of clusters in the first tier for $\mathrm{N}=7$.

Number of cells in large hexagon,

$$
L=\frac{A_{\text {large }}}{A_{\text {small }}}=\frac{\left(\frac{3 \sqrt{3}}{2}\right) \times 3 R^{2}\left(i^{2}+j^{2}+i \times j\right)}{\left(\frac{3 \sqrt{3}}{2}\right) \times R^{2}}=
$$$$
3\left(i^{2}+j^{2}+i \times j\right)
$$

It can be seen from Fig. 11, the total number of cells enclosed by the larger hexagon is

$$
\begin{aligned}
L & =N+6 \times\left[\frac{1}{3} \times N\right]=N+2 N=3 N=3\left(i^{2}+j^{2}+i \times j\right) \\
& \Rightarrow N=\left(i^{2}+j^{2}+i \times j\right)
\end{aligned}
$$

Where, $i$ and $j$ are the shift parameters and $N$ is the cluster size. The co-channel interference depends on the frequency reuse ratio shown in Fig. 12 and is given [6] by equation (10).

$q=\frac{D}{R}$ 


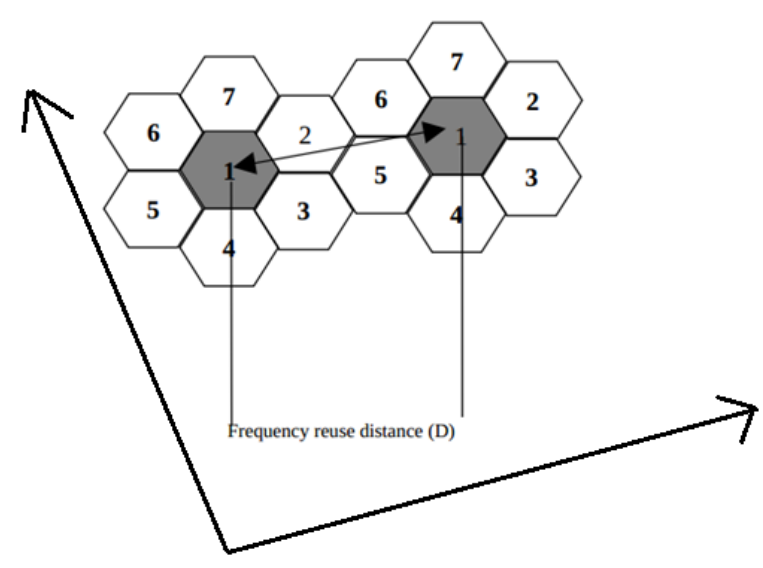

Fig. 12 Frequency reuse distance.

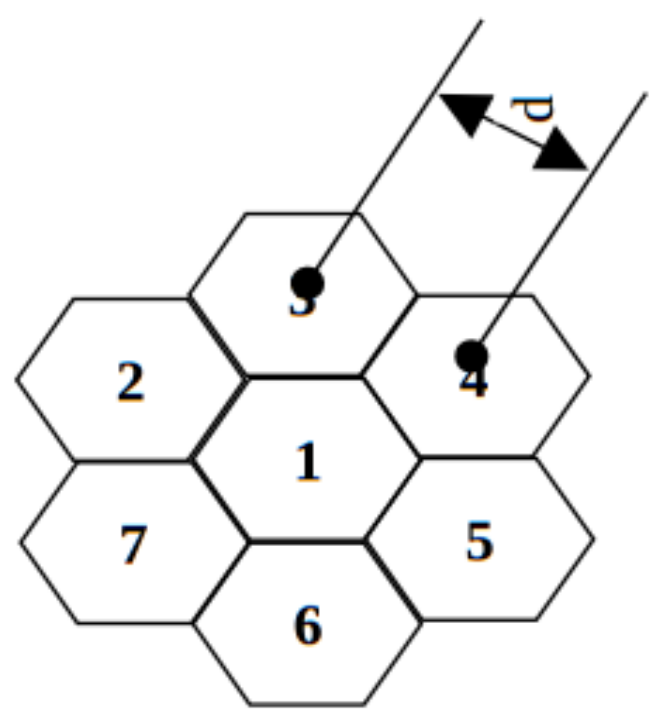

Fig. 13 Distance between two adjacent cells [4].

Let $\mathrm{d}$ be the distance between two cell centers of neighboring cells shown in Fig. 13. Therefore, putting $d=\sqrt{3} R$ and the relationship between $D, d$, and shift parameters is

$$
\begin{aligned}
& D^{2}=3 R^{2}\left(i^{2}+j^{2}+i \times j\right)=3 R^{2} N \\
& \Rightarrow 3 N=\frac{D^{2}}{R^{2}}=\left(\frac{D}{R}\right)^{2}=q^{2} \Rightarrow q=\sqrt{3 N}
\end{aligned}
$$

\subsubsection{Cell Sectoring}

The radio signals with equal power strength are transmitted to all directions in omni-directional antennas. But it is arduous to design this type of antennas. The directional antennas can be implemented to cover a region of 60 degrees or 120 degrees shown in Fig. 14.

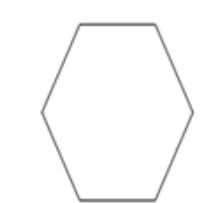

Omni-directional
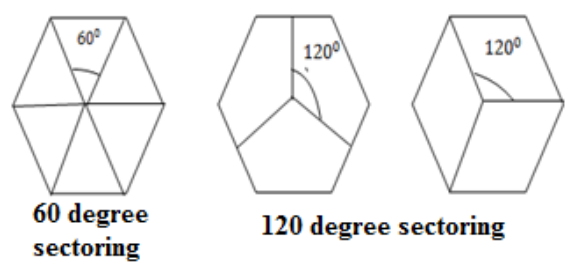

120 degree sectoring
The cells which are served by them are called sectored cells. There are two cases for observing the SIR performance with cell sectoring methods. In omni-directional case, the signal to interference ratio can be written [4] by equation (11).

$$
\frac{S}{I}=\frac{R^{-\delta}}{2(D-R)^{-\delta}+2 D^{-\delta}+2(D+R)^{-\delta}}
$$

Where, $\delta$ is the exponent of path loss. In three-sector case, the cell is divided into three sectors with three 120 degree directional antennas. Two interferers can be occurred in this case. Then, the signal to interference ratio can be written as equation (12).

$$
\frac{S}{I}=\frac{R^{-\delta}}{D^{-\delta}+(D+0.7 R)^{-\delta}}
$$

For six sector case, the cell is divided into six sectors with six 120 degree directional antennas. Only one interferer can be occurred in this case. Then, the signal to interference ratio will be as given in equation (13).

$$
\frac{S}{I}=\frac{R^{-\delta}}{(D+0.7 R)^{-\delta}}
$$

\subsubsection{Microcell Zone Concept}

The problem of sectoring can be addressed by another technique called the microcell zone concept shown in Fig. 15. A cell can be subdivided into micro cells per zone in this concept. Each microcell is coupled to the same base station unlike cell splitting through fiber optic line or microwave link. A directional antenna is used by each zone. When a cell phone makes a journey from one zone to another, the same channel will be retained. As a result no handoff is done.

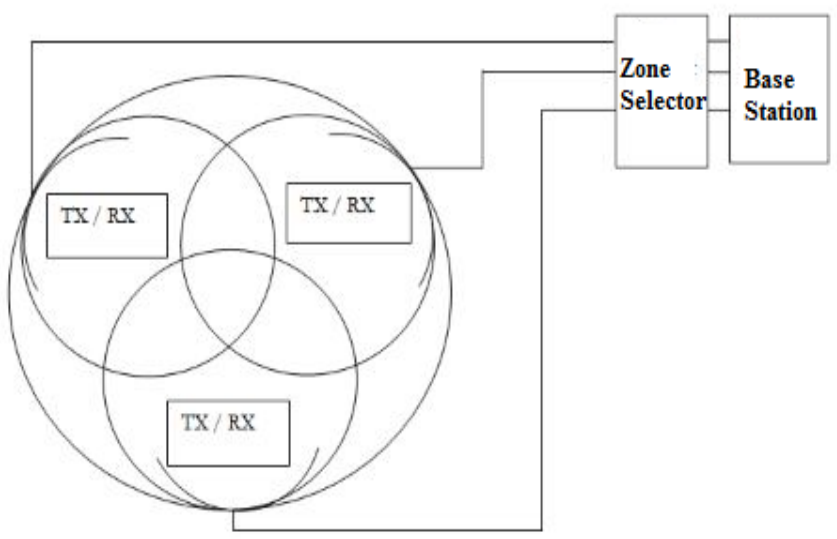

Fig. 15 Microcell zone concept [4].

In microcell zone method, no handoff is needed, because all zones are connected to the same Base-station (BS). Moreover, antennas use lesser transmitting power and they are directional. Thus Co-channel Interference (CCI) is decreased and signal quality and capacity is are improved. Thus call drop can be reduced. The base station is just switching from one microcell to another. By microcell zone technique, the system capacity can be defined by equation (14).

\section{System capacity}

$$
\begin{aligned}
& =\text { Capacity increase factor } \\
& \times \text { number of subscriber }
\end{aligned}
$$

Fig. 14 Cell sectoring [5]. 


\subsubsection{Queuing of handoffs:}

Instead of rejecting the handoff request calls, the request can be queued, when the new cell sites will busy. It is more fruitful algorithm than two-level handoff algorithm [4].

Let, $\frac{1}{\xi}$ is the mean calling time involving new requesting call and existing call for handoff expressed in seconds, $\kappa_{1}$ is the coming rate for originating calls, $\kappa_{2}$ is the coming rate for requesting calls of handoff, $Q_{1}$ is the queue size of originating calls, $Q_{2}$ is the queue size of requesting calls of handoff, and $M$ is the number of audio channels [4].

$A=\frac{\kappa_{1}+\kappa_{2}}{\xi}, a_{1}=\frac{\kappa_{1}}{\xi}, a_{2}=\frac{\kappa_{2}}{\xi}$

To observe the enhancement of handoff administration, the following three cases can be considered.

Case-1: When the originating calls and the requested handoff calls have no queue policy, then the blocking probability of originating and requested handoff calls will be [4]

$$
B_{o}=\frac{A^{M}}{M !} P(0) ; P(0)=\left(\sum_{m=0}^{M} \frac{a^{M}}{m !}\right)^{-1}
$$

Case-2: When the originating calls are queued but the handoff calls are not queued, the blocking probability of originating calls [4] will be

$$
\begin{aligned}
& B_{\text {oq }}=\left(\frac{a_{1}}{M}\right)^{Q_{1}} P_{\text {queue }}(0) ; P_{\text {queue }}(0) \\
& =\left[M ! \sum_{m=0}^{M-1} \frac{A^{m-N}}{m !}+\frac{1-\left(\frac{a_{1}}{M}\right)^{Q_{1}+1}}{1-\left(\frac{a_{1}}{M}\right)}\right]^{-1}
\end{aligned}
$$

Also the blocking probability of requested handoff calls will be

$$
\begin{aligned}
& B_{\text {oh }}=\frac{1-\left(\frac{a_{1}}{M}\right)^{Q_{1}+1}}{1-\left(\frac{a_{1}}{M}\right)} P_{\text {queue }}(0) ; P_{\text {queue }}(0) \\
&=\left[M ! \sum_{m=0}^{M-1} \frac{A^{m-M}}{m !}+\frac{1-\left(\frac{a_{1}}{M}\right)^{Q_{1}+1}}{1-\left(\frac{a_{1}}{M}\right)}\right]^{-1}
\end{aligned}
$$

Case-3: When the requested handoff calls are queued but the originating calls are not queued, then the blocking probability of requested handoff calls [4] will be

$$
\begin{aligned}
& B_{\text {hq }}=\left(\frac{a_{2}}{M}\right)^{Q_{2}} P_{\text {queue }}(0) ; P_{\text {queue }}(0) \\
&=\left[M ! \sum_{m=0}^{M-1} \frac{a^{m-M}}{m !}+\frac{1-\left(\frac{a_{1}}{M}\right)^{Q_{1}+1}}{1-\left(\frac{a_{1}}{M}\right)}\right]^{-1}
\end{aligned}
$$

Also the blocking probability of originating calls will be

$$
\begin{aligned}
& B_{\text {ho }}=\frac{1-\left(\frac{a_{2}}{M}\right)^{Q_{2}+1}}{1-\left(\frac{a_{2}}{M}\right)} P_{\text {queue }}(0) ; P_{\text {queue }}(0) \\
&=\left[M ! \sum_{m=0}^{M-1} \frac{A^{m-M}}{m !}+\frac{1-\left(\frac{a_{1}}{M}\right)^{Q_{1}+1}}{1-\left(\frac{a_{1}}{M}\right)}\right]^{-1}
\end{aligned}
$$

\section{Result and Discussion}

Dropped call rate and dropped call probability has been calculated using equations (4) and (6) shown in Table 1.
Table 1 Dropped call rate and dropped call probability versus network traffic.

\begin{tabular}{|c|c|c|}
\hline $\begin{array}{c}\text { Network Traffic, } \\
\boldsymbol{\lambda}_{\boldsymbol{t}}\end{array}$ & $\begin{array}{c}\text { Dropped Call } \\
\text { Rate, } \boldsymbol{V}_{\boldsymbol{d}}\end{array}$ & $\begin{array}{c}\text { Dropped Call } \\
\text { Probability, } \boldsymbol{P}_{\boldsymbol{d}}\end{array}$ \\
\hline 0 & 2.02 & $2 \times 10^{-5}$ \\
\hline 1 & 2.05 & $5 \times 10^{-4}$ \\
\hline 2 & 2.1 & $5 \times 10^{-3}$ \\
\hline 3 & 2.15 & $2.5 \times 10^{-2}$ \\
\hline 4 & 2.2 & $2 \times 10^{-2}$ \\
\hline 5 & 2.25 & $1.25 \times 10^{-2}$ \\
\hline
\end{tabular}

With different number of active users, the dropped call probability can be calculated from equation (6) shown in Table 2.

Table 2 Dropped call probability versus number of users.

\begin{tabular}{|c|c|}
\hline Number of Users, $\boldsymbol{k}$ & Dropped Call Probability, $\boldsymbol{P}_{\boldsymbol{d}}$ \\
\hline 10 & $2.605 \times 10^{-2}$ \\
\hline 15 & $2.620 \times 10^{-2}$ \\
\hline 20 & $2.642 \times 10^{-2}$ \\
\hline 25 & $2.660 \times 10^{-2}$ \\
\hline 30 & $2.665 \times 10^{-2}$ \\
\hline
\end{tabular}

Channel utilization factors can be found from equation (5) and with channel utilization factor $(\rho)$, the dropped call probability can be calculated from equation (6) shown in Table 3 .

Table 3 Dropped call probability versus channel utilization factor.

\begin{tabular}{|c|c|}
\hline $\begin{array}{c}\text { Channel Utilization } \\
\text { Factor, } \boldsymbol{\rho}\end{array}$ & $\begin{array}{c}\text { Dropped Call Probability, } \\
\boldsymbol{P}_{\boldsymbol{d}}\end{array}$ \\
\hline 0.96 & $1.7 \%$ \\
\hline 0.92 & $3.5 \%$ \\
\hline 0.90 & $3.9 \%$ \\
\hline 0.88 & $4.5 \%$ \\
\hline 0.86 & $5.3 \%$ \\
\hline 0.84 & $6.1 \%$ \\
\hline
\end{tabular}

3.1 Mathematical analysis of cell splitting

Let, the total coverage area is $2000 \mathrm{~km}^{2}$, total available channel is 320 , call holding time is 120 seconds, path loss exponent is 4 . Let the cell radius is $8 \mathrm{~km}$ and the frequency pattern is $(2,1)$.

From equation (7), the distance between a particular cell and the nearest co-channel, $D=36.66 \mathrm{~km} \approx 37 \mathrm{~km}$. The frequency reuse ratio is $q=\frac{D}{R}=\frac{37}{8}=4.58$. Area of small hexagon $A_{\text {small }}=\frac{3 \sqrt{3}}{2} R^{2}=\frac{3 \sqrt{3}}{2} \times 8^{2}=166.2768 \mathrm{~km}^{2}$

For seven cells cluster, area of cluster $=166.3 \times 7=$ $1164.1 \mathrm{~km}^{2}$. Number of clusters for covering total area $=$ $\frac{2000 \mathrm{~km}^{2}}{1164.1 \mathrm{~km}^{2}}=1.718 \approx 2$.

$$
\text { System Capacity = number of cluster } \times
$$


The signal to interference ratio from equation (3), $\frac{S}{I}=$ $\frac{(3 N)^{\gamma / 2}}{6}=\frac{(3 \times 2)^{4 / 2}}{6}=7.78 \mathrm{~dB}$

Number of channels per cell site $=\frac{320}{2}=160$

From the Erlang B traffic table [7], for 160 channels, Traffic load $=146.6$ erlangs

The number of calls per hour per cell is $\frac{N_{\text {call }} \times 120}{3600}=$ $(1-0.02) \times 146.6$ erlangs

$$
\Rightarrow N_{\text {call }}=4310.04 \approx 4310
$$

Average call arrival rate, $\lambda=\frac{4310 \text { requests }}{3600} \times 120=$ 143.667. $\mathrm{N}=162$.

From Erlang B traffic table [7], Number of serving channels, Blocking prob
$\frac{A^{N} / A !}{\sum_{i=0}^{N}\left(\frac{A^{i}}{i !}\right)}=1.2 \%$ and

The performance of cell splitting for this system can be summarized using equations from (7) to (10) as shown in Table 4.

Table 4 Performance of cell splitting technique.

\begin{tabular}{|l|c|c|c|}
\hline \multirow{2}{*}{$\begin{array}{l}\text { Parameters to be } \\
\text { found }\end{array}$} & \multicolumn{3}{|c|}{ Cell radius } \\
\cline { 2 - 4 } Area of Clusters & $1164.1 \mathrm{~km}^{2}$ & $\begin{array}{c}290.983 \\
\mathrm{~km}^{2}\end{array}$ & $\begin{array}{c}72.74 \\
\mathrm{~km}^{2}\end{array}$ \\
\hline Number of Clusters & 2 & 7 & 28 \\
\hline $\begin{array}{l}\text { Signal to } \\
\text { Interference ratio } \\
\text { (SIR) }\end{array}$ & $7.78 \mathrm{~dB}$ & $18.66 \mathrm{~dB}$ & $\begin{array}{c}30.70 \\
\mathrm{~dB}\end{array}$ \\
\hline $\begin{array}{l}\text { Blocking } \\
\text { Probability }\end{array}$ & $1.2 \%$ & $0.9 \%$ & $0.02 \%$ \\
\hline System Capacity & 640 & 2240 & 6960 \\
\hline
\end{tabular}

From Table 4, the performance of cell splitting technique can be discussed.

The blocking probability decreases (see Fig. 16), as the number of channels increase. Thus the cellular capacity is increased that reduces the call drop. For 40 call requests, the blocking probability is increased compared to the 30 call requests with the same number of channels. If we further increase the number of channels with 40 call requests, the blocking probability will be decreased.

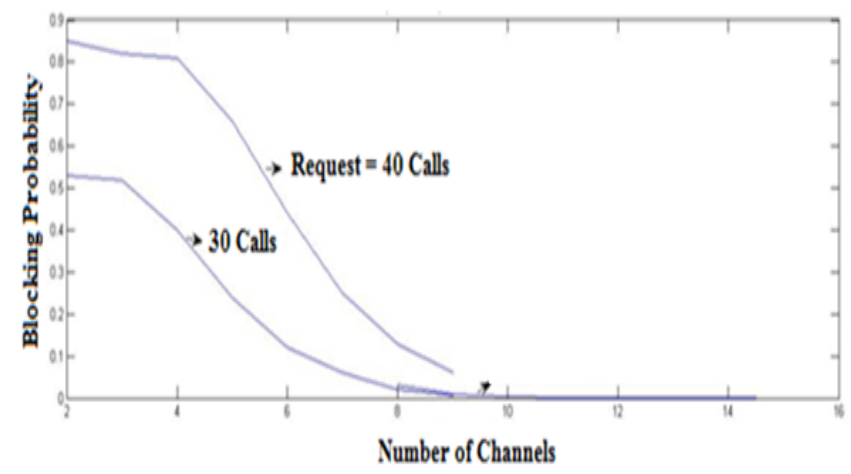

Fig. 16 Blocking probability versus number of channels.
Thus the handover failure rate can be successfully reduced in terms of call drop reduction method.

The capacity of a cellular system can be found. As the number of cells increase, the capacity increases (see Fig. 17). Using cell splitting technique, the number of cells can be increased.

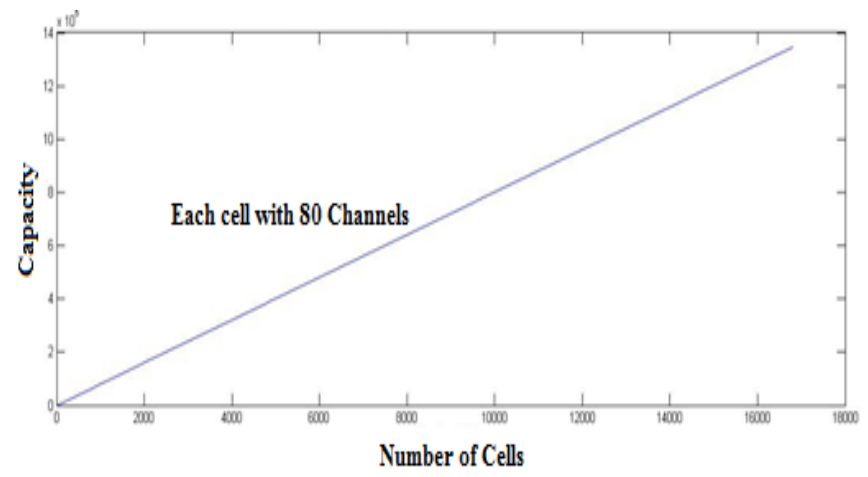

Fig. 17 Capacity versus number of cells.

With smaller size of the cell, a large number of users can use the cells. Thus higher capacity can be ensured in cell splitting technique. With increasing the number of cells, the number of clusters will be increased and hence the number of channels and capacity will be increased.

According to equation (3), signal to interference ratio (SIR) in cellular network can be analyzed. As the cell radius increases, the cell reuse factor decreases and so the signal to interference ratio is reduced (see Fig. 18). If the cell is divided into many smaller cells, the cell radius is decreased and thus the signal to interference ratio is improved.

There is restricted interference with small cells but there is huge interference with larger cells. As cell radius decreases, signal to interference ratio increases. So in a particular dense populated area, this technique can be used to improve the signal to interference ratio and reduces the effect of call drop.

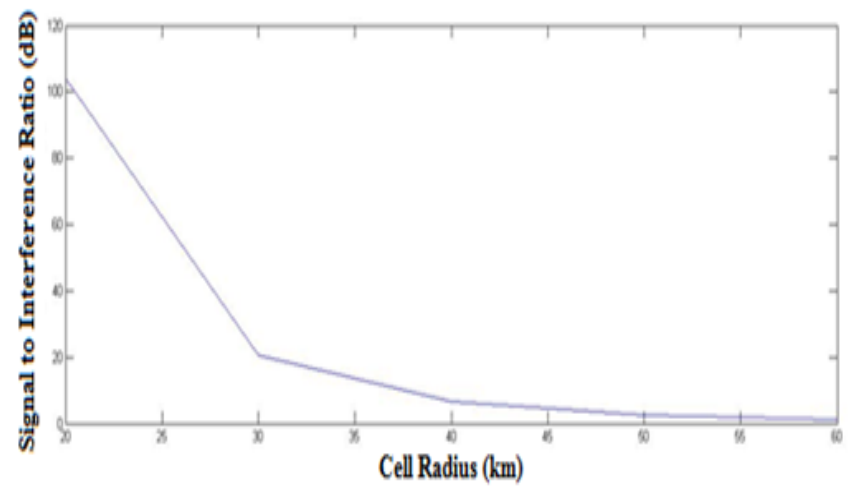

Fig. 18 SIR versus cell radius.

\subsection{Mathematical analysis of Cell Sectoring}

Assume that the frequency reuse pattern is $(i=2, j=1)$, path loss exponent $\gamma=4$ and the radius of the cell is $2 \mathrm{~km}$. From equation (7), the distance between a particular cell and the nearest co-channel, $D=9.165 \mathrm{~km}$. Frequency reuse ratio, $q=\frac{D}{R}=\frac{9.165 \mathrm{~km}}{2 \mathrm{~km}}=4.5825$ 
From equation (11), with omni-directional antenna, the S/I ratio can be given as

$$
\frac{S}{I}=\frac{R^{-\gamma}}{2(D-R)^{-\gamma}+2 D^{-\gamma}+2(D+R)^{-\gamma}} \Rightarrow \frac{1}{2(q-1)^{-4}+2 q^{-4}+2(q+1)^{-4}}=
$$

$18.7 d B$

From equation (12), with $120^{\circ}$ sectored antenna, the S/I ratio will be

$\frac{S}{I}=\frac{R^{-\gamma}}{D^{-\gamma}+(D+0.7 R)^{-\gamma}}=24.48 d B$ will be

From equation (13), with $60^{\circ}$ sectored antenna, the S/I ratio $\frac{S}{I}=\frac{R^{-\gamma}}{(D+0.7 R)^{-\gamma}}=29 d B$

Assume traffic per user is $40 \mathrm{mErl}$ or $0.04 \mathrm{Erl}$, the grade of service (GOS) is $2 \%$ and the total number of traffic channels is 320.

For omni-directional antenna with $\mathrm{N}=7$ :

$\begin{array}{ccc}\text { Voice channels } & \text { per } & \text { sector } \\ \frac{3 \text { Allocated channels }}{\text { Cluster size } \times \text { number of antenna }}=\frac{320}{7 \times 1}=45.714\end{array}$

[6] $=$

Offered traffic load per cell [6]

$=$ number of antenna $\times$

offered traffic load per sector with $2 \%$ blocking $=$

$1 \times 36.1=36.5$

The traffic load will be $\frac{N_{\text {call }} \times 120}{3600}=(1-.02) \times 36.5$, or $N_{\text {call }}=358$

Offered traffic load (5), $A=\frac{\text { traffic request }}{3600} \times$ call holding time $=\frac{358}{3600} \times 120=11.933$

From the Erlang-B traffic table [7], Number of serving channels, $N=20$

Blocking probability (from equation (1)), $B(N, A)=$ $\frac{A^{N} /{ }_{A !}}{\sum_{i=0}^{N}\left(\frac{A^{i}}{i !}\right)}=2 \%$

No of channels per cell $=320 / 7=46$.

With $2 \%$ blocking, traffic supported per cell $=36.5 \mathrm{Erl}$ and total no of users supported per cell $=(36.5 / 0.04)=913$.

Assume that a cellular service provider decides to use a digital TDMA scheme which can tolerate a signal to interference ratio of $15 d B$ in the worst case. The optimal value of $\mathrm{N}$ can be calculated for omni-directional antennas, $120^{\circ}$ sectored antennas and $60^{\circ}$ sectored antennas. Assume a path loss exponent $\gamma=4$.

\subsubsection{With omni-directional antenna} cells.

Assuming six interferers from the first tire of co-channel

The value of $\mathrm{N}$ is $\frac{S}{I}=\frac{\left(\frac{D}{R}\right)^{\gamma}}{I_{0}}=\frac{(\sqrt{3 N})^{\gamma}}{I_{0}} \Rightarrow N=4.592$.
Since we have to choose higher possible value to satisfy the $S / I$ requirement,

With $N=7, \frac{S}{I}=\frac{(\sqrt{3 N})^{\gamma}}{I_{0}}=\frac{(\sqrt{3 \times 7})^{4}}{6}=18.66 \mathrm{~dB}$.

Where $18.66 d B$ is better than the requirement. In this type of antenna, choose $N=7$

\subsubsection{With $120^{\circ}$ Sectored antenna}

With $120^{\circ}$ sectoring and $\mathrm{N}=4$, there are 2 interferers in the first tier of co channel cells.

Taking $I_{0}=2$ in the expression, $\frac{S}{I}=\frac{(\sqrt{3 N})^{n}}{I_{0}}=\frac{(\sqrt{3 \times 4})^{4}}{2}=$ $18.57 \mathrm{~dB}$ With $120^{\circ}$ sectoring, the $S / I$ obtained is better than required; so $N=4$ can be used.

We have to again check for the frequency reuse pattern $(i=1, j=1)$ and $N=3$.

Taking $I_{0}=3$ in the expression, $\frac{S}{I}=\frac{(\sqrt{3 N})^{n}}{I_{0}}=\frac{(\sqrt{3 \times 3})^{4}}{3}=$ $14.314 d B$. Since it is lower than the required value; so $N=3$ cannot be used.

\subsubsection{With $60^{\circ}$ Sectored antenna}

With $60^{\circ}$ sectoring and $\mathrm{N}=4$, there are 1 interferer in the first tier of co-channel cells.

Taking $I_{0}=1$ in the expression, $\frac{S}{I}=\frac{(\sqrt{3 N})^{n}}{I_{0}}=\frac{(\sqrt{3 \times 4})^{4}}{1}=$ $21.57 \mathrm{~dB}$. With $60^{\circ}$ sectoring, the $\mathrm{S} / \mathrm{I}$ obtained is better than required. So $\mathrm{N}=4$ can be used.

We have to again check for the frequency reuse pattern $(i=1, j=1$ ) and $N=3$.

Taking $I_{0}=2$ in the expression, $\frac{S}{I}=\frac{(\sqrt{3 N})^{n}}{I_{0}}=\frac{(\sqrt{3 \times 4})^{4}}{2}=$ $16.074 d B$

Since it is higher than the required value, $\mathrm{N}=3$ can be used.

Table 5 Optimization of cluster size, $\mathrm{N}$.

\begin{tabular}{|c|c|}
\hline $\begin{array}{l}\text { With } 120^{\circ} \text { sectored } \\
\text { antenna }(\mathrm{N}=4)\end{array}$ & $\begin{array}{l}\text { With } 60{ }^{\circ} \text { sectored } \\
\text { antenna }(\mathrm{N}=3)\end{array}$ \\
\hline$>\begin{array}{l}\text { No of channels per } \\
\text { cell }=420 / 4=105\end{array}$ & $\begin{array}{l}\text { No of channels per } \\
\text { cell }=420 / 3=140\end{array}$ \\
\hline $\begin{array}{l}\text { No of channels per } \\
\text { sector }=105 / 3=35 \\
\text { With } 2 \% \text { blocking, }\end{array}$ & $\begin{array}{l}\text { No of channels per } \\
\text { sector }=140 / 6=23.33 \approx 23 \\
\text { With } 2 \% \text { blocking, }\end{array}$ \\
\hline $\begin{array}{l}\text { Traffic supported by one } \\
\text { sector }=26.44 \mathrm{Erl}\end{array}$ & $\begin{array}{l}\text { Traffic supported by } \\
\text { one sector }=15.76 \mathrm{Erl}\end{array}$ \\
\hline $\begin{array}{l}\text { Traffic supported by one } \\
\text { cell }=26.44 * 3=79.32\end{array}$ & $\begin{array}{l}\text { Traffic supported by } \\
\text { one cell } \\
15.76^{*} 6=94.56\end{array}=$ \\
\hline $\begin{array}{l}\text { Total no of users } \\
\text { supported per cell = } \\
(79.32 / 0.04)=1983\end{array}$ & $\begin{array}{l}\text { Total no of users } \\
\text { supported per cell = } \\
(94.56 / 0.04)=2364\end{array}$ \\
\hline
\end{tabular}

For the given number of channels in the system, $60^{\circ}$ sectoring with $\mathrm{N}=3$ gives the largest capacity shown in Table 5 . With this optimum value of $\mathrm{N}$, the performance of cell sectoring can be analyzed shown in 
Table 6.

Table 6 Performance of cell sectoring with optimum value.

\begin{tabular}{|c|c|c|c|}
\hline Type of antenna & $\begin{array}{c}\text { Omni- } \\
\text { directional } \\
\text { antenna }\end{array}$ & $\begin{array}{c}\mathbf{1 2 0}^{\circ} \\
\text { sectoring }\end{array}$ & $\begin{array}{c}\mathbf{6 0}^{\circ} \\
\text { sectoring }^{\circ}\end{array}$ \\
\hline $\begin{array}{c}\text { Number of } \\
\text { interferers in the } \\
\text { first tier co-channel } \\
\text { cells }\end{array}$ & 6 & 2 & 1 \\
\hline $\begin{array}{c}\text { Optimum value of N } \\
\text { for S/I=15dB }\end{array}$ & 7 & 4 & 3 \\
\hline $\begin{array}{c}\text { System Capacity } \\
\text { with optimum value } \\
\text { of N }\end{array}$ & 913 & 1983 & 2364 \\
\hline
\end{tabular}

Assume that the frequency reuse pattern is $(i=2, j=1)$, path loss exponent $\gamma=4$ and the radius of the cell is $2 \mathrm{~km}$. The performance of cell sectoring for this system can be summarized from equation (11), (12) and (13) as shown in Table 7.

Table 7 Performance of cell sectoring.

\begin{tabular}{|c|c|c|c|}
\hline $\begin{array}{c}\text { Parameters } \\
\text { to be found }\end{array}$ & $\begin{array}{c}\text { Omni- } \\
\text { directional } \\
\text { Antenna }\end{array}$ & $\begin{array}{c}\text { Three } \\
\text { sectored } \\
\text { Antenna }\end{array}$ & $\begin{array}{c}\text { Six sectored } \\
\text { Antenna }\end{array}$ \\
\hline $\begin{array}{c}\text { Blocking } \\
\text { Probability }\end{array}$ & $2 \%$ & $1.5 \%$ & $0.2 \%$ \\
\hline $\begin{array}{c}\text { System } \\
\text { Capacity }\end{array}$ & 913 & 2663 & 4575 \\
\hline $\begin{array}{c}\text { Signal to } \\
\text { interference } \\
\text { ratio }\end{array}$ & $18.7 \mathrm{~dB}$ & $24.48 \mathrm{~dB}$ & $29 \mathrm{~dB}$ \\
\hline
\end{tabular}

From equations (11), (12) and (13), the signal to interference ratio can be analyzed with respect to cluster size given in Fig. 19.

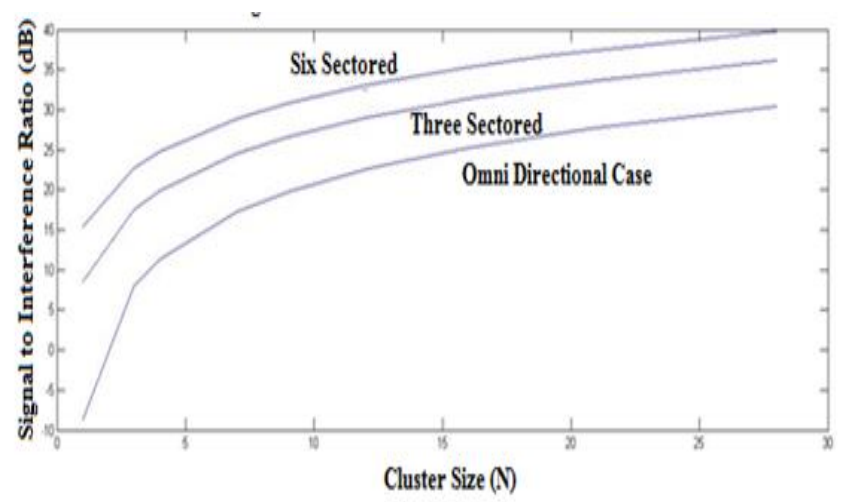

Fig. 19 SIR versus cluster size.

60 degree sectored configuration can be used under heavy traffic to reduce co-channel interference according to equation (13) (See Fig. 10). It can be concluded that the 60 degree sectored configuration with $\mathrm{N}=3$ will give the largest capacity.

\subsection{Mathematical analysis of Microcell Zone Concept}

According to microcell zone concept, consider three zones within one cell created. Thus the supported number of subscribers can be increased without making any interference problem. According to equation (14), the system capacity can be increased by microcell zone technique. As the size of the cluster decreases, the system capacity increases linearly (see Fig. 20). Thus the supported number of subscribers can be increased without making any interference problem. Same channel will be kept for the call progress by the cell phone user, when users move from one zone to another zone. So, there is no need of handoff within the microcell zone.

Assume that the desired Signal-to-interference ratio is 18 $\mathrm{dB}$, the number of subscriber is 1000 and the path loss exponent $\gamma$ is 4 . For simplicity consider the three zones per cell. To achieve Signal-to-interference ratio of $18 \mathrm{~dB}$, the cluster size $\mathrm{N}$ should be 7. According to microcell zone concept, three zones within one cell created.

For new cluster size $\mathrm{N}=3$, Capacity increase factor $=\frac{7}{3}=$ 2.33

By microcell zone technique (from equation (14))

System Capacity = Capacity increase factor $\times$ number of subscriber $=2.33 \times 1000=2330$

Thus the supported number of subscribers can be increased without making any interference problem.

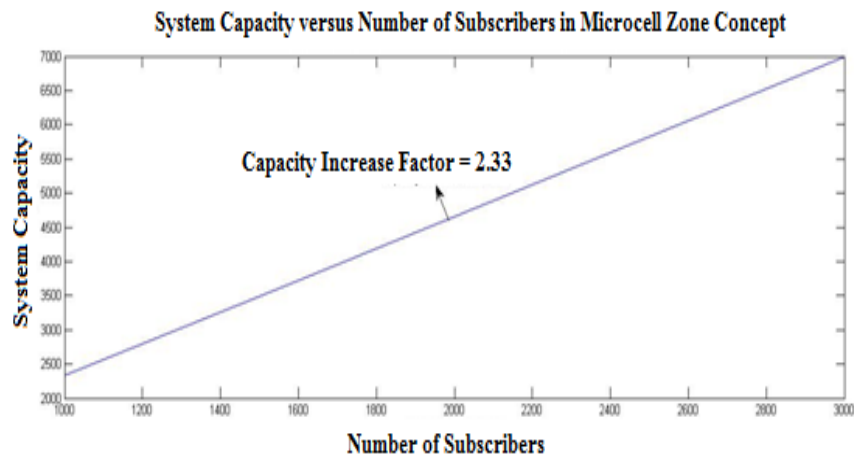

Fig. 20 System capacity with the number of subscribers.

3.4 Mathematical analysis of Queuing Handoffs

Consider the number of channels at the cell site is 70 , the call holding time is $101 \mathrm{~s}$, the number of originating calls attempted per hour is 2270 and the number of handoff calls attempted per hour is 80 . Then, $A=\frac{\lambda_{1}+\lambda_{2}}{\mu}=(2270+80) \times$ $\frac{101}{3600}=65.80, \quad b_{1}=\frac{\lambda_{1}}{\mu}=2270 \times \frac{101}{3600}=63.60, \quad b_{2}=\frac{\lambda_{2}}{\mu}=$ $80 \times \frac{101}{3600}=2.245$

3.4.1 Queuing the originating calls but not the handoff calls

Let the size of the queue for originating calls is 16 . Using MATLAB simulation,

From equation (15), the blocking probability for originating calls is $P_{q}(0)=\left[N ! \sum_{n=0}^{N-1} \frac{a^{n-N}}{n !}+\frac{1-\left(\frac{b_{1}}{N}\right)^{M_{1}+1}}{1-\left(\frac{b_{1}}{N}\right)}\right]^{-1}=0.04$ and $B_{o q}=\left(\frac{63.60}{70}\right)^{16} \times 0.04=0.012$

From equation (16), the blocking probability for handoff calls is $\quad B_{o h}=\frac{1-\left(\frac{b_{1}}{N}\right)^{M_{1}+1}}{1-\left(\frac{b_{1}}{N}\right)} P_{q}(0)=\frac{1-\left(\frac{63.60}{70}\right)^{16+1}}{1-\left(\frac{63.60}{70}\right)} \times 0.04=$ 0.3534

Let the size of the queue for originating calls is 10 . Using MATLAB simulation, 
The blocking probability for originating calls is $P_{q}(0)=$ $\left[N ! \sum_{n=0}^{N-1} \frac{a^{n-N}}{n !}+\frac{1-\left(\frac{b_{1}}{N}\right)^{M_{1}+1}}{1-\left(\frac{b_{1}}{N}\right)}\right]^{-1}=0.044 \quad$ and $\quad B_{o q}=$ $\left(\frac{63.60}{70}\right)^{10} \times 0.044=0.016$

The blocking probability for handoff calls is $B_{o h}=$ $\frac{1-\left(\frac{b_{1}}{N}\right)^{M_{1}+1}}{1-\left(\frac{b_{1}}{N}\right)} P_{q}(0)=\frac{1-\left(\frac{63.60}{70}\right)^{10+1}}{1-\left(\frac{63.60}{70}\right)} \times 0.044=0.3186$

3.4.2 Queuing the handoff calls but not the originating calls

Let the size of the queue for handoff calls is 2 . Using MATLAB simulation,

$P_{q}(0)=\left[N ! \sum_{n=0}^{N-1} \frac{a^{n-N}}{n !}+\frac{1-\left(\frac{b_{1}}{N}\right)^{M_{1}+1}}{1-\left(\frac{b_{1}}{N}\right)}\right]^{-1}=0.058$

From equation (18), the blocking probability for handoff calls is $B_{h q}=\left(\frac{b_{2}}{N}\right)^{M_{2}} P_{q}(0)=0.0000593$

From equation (19), the blocking probability for originating calls is $\quad B_{h o}=\frac{1-\left(\frac{b_{2}}{N}\right)^{M_{2}+1}}{1-\left(\frac{b_{2}}{N}\right)} P_{q}(0)=\frac{1-\left(\frac{2.24}{70}\right)^{2+1}}{1-\left(\frac{2.24}{70}\right)} \times 0.058=$ 0.05938

Let the size of the queue for handoff calls is 3. Using MATLAB simulation, $\quad P_{q}(0)=\left[N ! \sum_{n=0}^{N-1} \frac{a^{n-N}}{n !}+\right.$ $\left.\frac{1-\left(\frac{b_{1}}{N}\right)^{M_{1}+1}}{1-\left(\frac{b_{1}}{N}\right)}\right]^{-1}=0.058$

The blocking probability for handoff calls is $B_{h q}=$ $\left(\frac{2.24}{70}\right)^{3} \times 0.058=0.000001900$

The blocking probability for originating calls is $B_{h o}=$ $\frac{1-\left(\frac{b_{2}}{N}\right)^{M_{2}+1}}{1-\left(\frac{b_{2}}{N}\right)} P_{q}(0)=\frac{1-\left(\frac{2.24}{70}\right)^{3+1}}{1-\left(\frac{2.24}{70}\right)} \times 0.058=0.05991$

According to equation (16) and (17), the blocking probability of new originating calls and the blocking probability of requested handoff calls can be found (see Fig. 21 and Fig. 22).

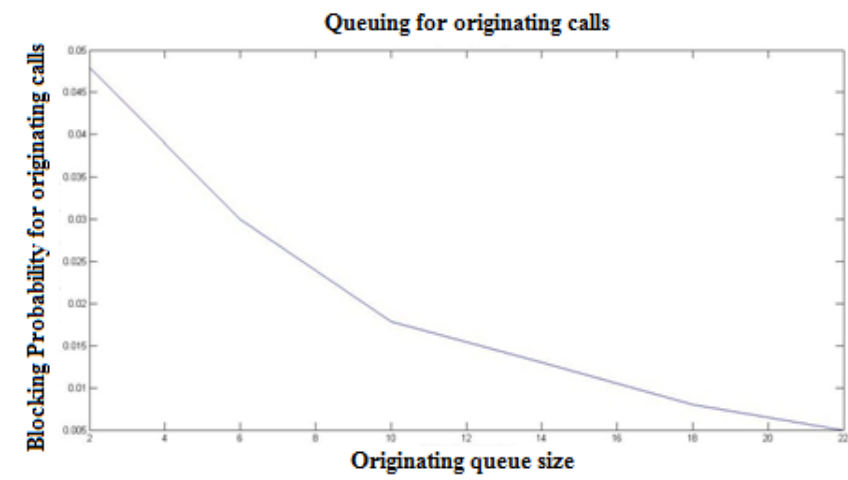

Fig. 21 Blocking probability of originating call, when only the originating calls are queued.

According to equation (18), the blocking probability of requested handoff calls and the blocking probability of new originating calls can be found (see Fig. 23 and Fig. 24).

The blocking probability of requested handoff calls will increase with the queuing of new originating calls. In case of call drop, this is the main problem. The blocking probability of requested handoff calls will decrease with the queuing of requested handoff calls (see Fig. 14). Also it does not affect the blocking probability of new originating calls (see Fig. 15). It can be concluded that the queuing of requested handoff calls is more important than the queuing of new originating call. Because customers become more upset for call drop than call blockings.

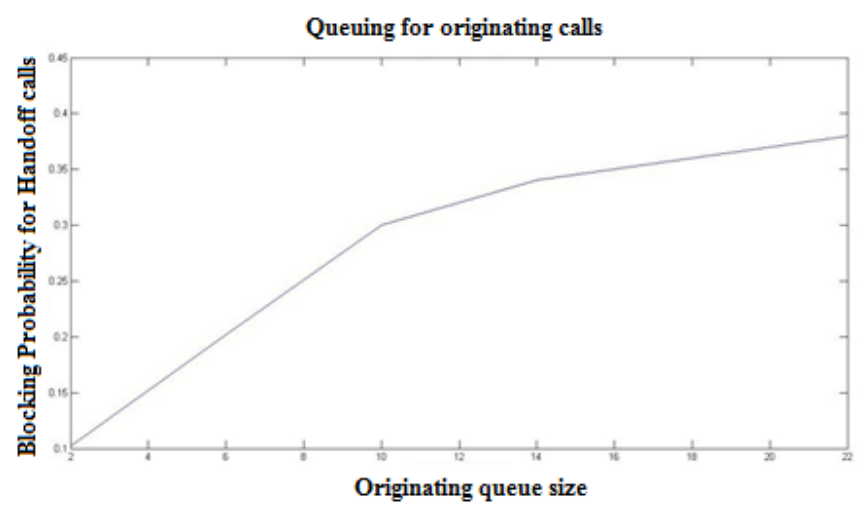

Fig. 22 Blocking probability of requested handoff calls, when only the originating calls are queued.

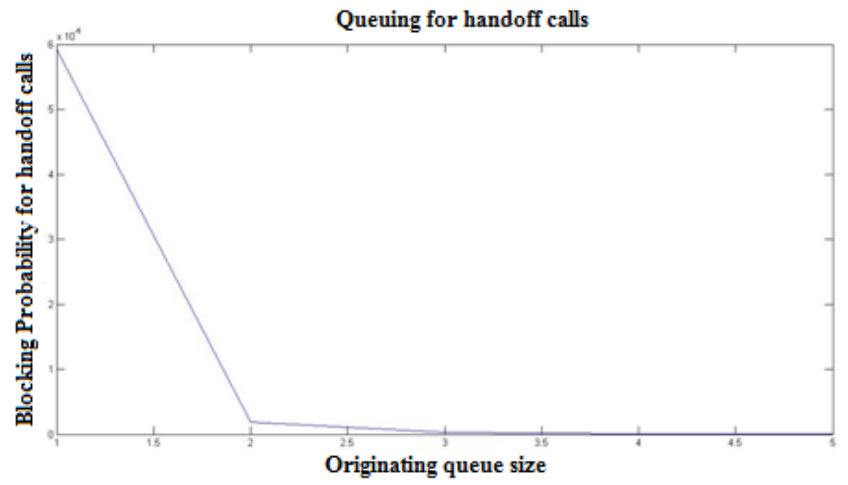

Fig. 23 Blocking probability of requested handoff calls, when only the requested handoff calls are queued.

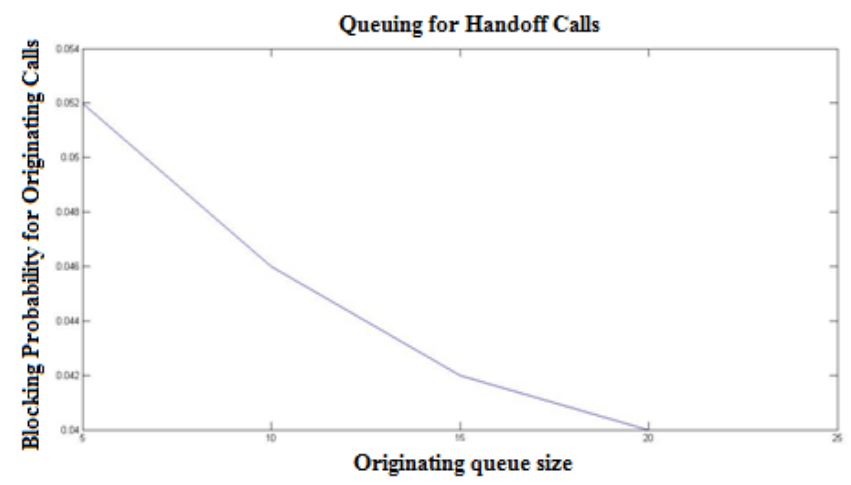

Fig. 24 Blocking probability of new originating calls, when only the requested handoff calls are queued.

\section{Conclusion}

To reduce dropped call probability in cellular network, a mathematical model has developed in this paper considering different factors causing call drop incidents. Then the parameters have been identified by which call drop probability can be minimized by improving those. In this paper, some efficient techniques such as cell splitting, cell sectoring, micro cell zone 
concept have analyzed mathematically to increase the system capacity and signal to interference ratio. In cell splitting technique, the cellular capacity will be increased with increasing number of channels which can be increased by splitting the larger cell into smaller cell. As a result the cell radius has decreased which in turns improve the signal to interference ratio. In cell sectoring technique, co-channel interference has reduced by introducing 60 degree sectored configuration cell under heavy traffic. Mathematically it has proven that the 60 degree sectored configuration with cluster size of 3 has given the largest capacity which in turns improved the cellular network. In microcell zone concept, due to decrease of the cluster size, also the system capacity has increased linearly. Thus subscriber numbers have increased without making any interference problem. The same channel has kept for the call progress by the cell phone user, when users move from one zone to another zone. So, there is no need of handoff within the microcell zone. In handoff queuing methods, the blocking probability of requested handoff calls has increased with increasing the queuing of new originating calls. The blocking probability of requested handoff calls will decrease with increasing the queuing of requested handoff calls. Also it does not affect the blocking probability of new originating calls. It has concluded that the queuing of requested handoff calls is more important than the queuing of new originating call. This work will help the network designer to implement an analytical model with better performance in terms of system capacity and signal quality.

\section{References}

[1] Gaur. P.. 2016. A review of menace of call drons in India and nossible wavs to minimize it. Int. J. Math. Eng. Manag. Sci, 1(3), pp.130-138.

[2] Ohaneme, C.O., Onoh, G.N., Ifeagwu, E.N. and Eneh, I.I., 2012. Improving channel capacity of a Cellular system using Cell Splitting. International Journal of Scientific and Engineering Research, 3(5), pp.1-8.

[3] Jatin, K., 2016. Study and Analysis of Call dropping and Handover Problem in cellular system. International Journal of Advanced Research in Computer Engineering \& Technology, 5(6), pp.1776-1777.

[4] Garg, V., 2010. Wireless communications \& networking. Elsevier.

[5] Agrawal, D.P. and Zeng, Q.A., 2015. Introduction to wireless and mobile systems. Cengage learning.

[6] Boggia, G., Camarda, P. and D'alconzo, A., 2007. Modeling of call dropping in well-established cellular networks. EURASIP Journal on Wireless Communications and Networking, 2007, pp.1-11.

[7] Angus, I., 2001. An introduction to Erlang B and Erlang C. Telemanagement, 187, pp.6-8. 